\title{
EL CARÁCTER TRASCENDENTAL DE LA REFLEXIÓN CRÍTICA Y DE LA REFLEXIÓN DE LA VIDA
}

\section{THE TRANSCENDENTAL NATURE OF CRITICAL REFLECTION AND REFLECTION ON LIFE}

\author{
Juan José Bautista Segales ${ }^{1}$ \\ Universidad Autónoma de la Ciudad de México \\ juanjobautista@hotmail.com
}

Recibido: 29 de junio del 2017 / Aceptado: 15 de julio del 2017

Publicado 7 de noviembre del 2017.

Al maestro Karl-Otto Apel
In memoriam

1922-2017

Resumen: Este artículo fue escrito tras la muerte de Karl-Otto Apel. El autor hace un recuento del proceso de lectura de los escritos de dicho filósofo alemán, llevado a cabo por el profesor Enrique Dussel y un grupo de sus estudiantes, como preparación para discutir con el propio Apel, quien estuvo en México en un par de ocasiones. Luego, pasa a abordar el giro pragmático para mostrar cómo, a través de este y de las discusiones con el propio Apel, Dussel y quien escribe se replantearon asuntos fundamentales para avanzar, cada uno en su línea argumentativa, con su desarrollo teórico.

Palabras clave: giro pragmático, ética de la liberación, comunidad ideal de comunicación, filosofía moderna, racionalidad de la vida.

1 Juan José Bautista Segales es boliviano-aymara, estudió Ciencias Sociales en la Universidad Mayor de San Andrés y se doctoró en Filosofía en la Universidad Nacional Autónoma de México, con una tesis sobre el problema del conocimiento en América Latina. Trabaja en la Universidad Autónoma de la Ciudad de México en donde imparte la Cátedra Enrique Dussel, y en la Universidad Autónoma de México. Fue co-fundador de la revista Autodeterminación y tiene numerosos artículos y ensayos académicos publicados durante su carrera. Le fue otorgado el Premio Libertador 2016 por su libro ¿Qué significa pensar desde América Latina? 
Summary: This article was written following the death of Karl-Otto Apel. The author recounts the reading process of said philosopher's writings by Enrique Dussel and a group of his students as preparation to discuss them with the same Apel, who visited Mexico on a few occasions. Then, he approaches the pragmatic turn to demonstrate how, through the latter and the discussions with Apel himself, Dussel and the writer rethink fundamental issues in order to move forward, each in their own line of argument, with their theoretical development.

Keywords: pragmatic turn, ethics of liberation, ideal communication community, modern philosophy, material rationality of life.

Cuando el profesor Enrique Dussel llegó, a fines del año 89, muy entusiasmado, comentándonos a los integrantes de su seminario que había tenido un diálogo con un tal Karl-Otto Apel, en Alemania, y que teníamos que hacer un seminario acerca de su obra todo el año 90, como preparación para otro seminario con él en persona en el 91, aquí en México, muchos de nosotros -como en mi caso- nos quedamos con la boca abierta, porque no sabíamos quién era ese señor ni de qué trataba su obra. Para nosotros, como para muchos de nuestra generación, era un total desconocido.

Como estábamos casi terminado nuestro seminario con el profesor Dussel sobre la obra de Marx, en noviembre del 89, hacer la transición hacia otro seminario con otro tema o pensador no fue tan problemático. Empezamos en enero de 1990. Lo que me llamó la atención fue que, en la sesión inicial del seminario, en la UAM-Iztapalapa, luego de repartirnos entre todos los participantes los textos, capítulos o partes de libros que teníamos que exponer, empezamos, como es lógico, con la introducción de La transformación de la filosofía2 (Apel, 1985). Y como ya era costumbre del seminario, el -con su texto ya preparado sobre la introducción, que también todos habíamos leído-, estaba listo para escuchar y discutir su presentación. Pero el profesor Dussel detuvo un momento la sesión y preguntó a todos: “Alguien ha entendido de qué trata esta introducción?", y la respuesta fue un silencio absoluto. Inmediatamente dijo: "Qué bien, porque yo tampoco entendí nada". Lo normal habría sido que, en una circunstancia como esa, el profesor se las hubiese dado de gran conocedor y hasta de muy experto en la obra de Apel, o del giro pragmático, pero no. Por eso, me llamó siempre

2 Esperemos que con el fallecimiento del profesor Apel, Taurus u otra editorial se digne publicarlos, pues están totalmente agotados hace mucho tiempo. 
la atención la honestidad con la que Dussel dijo en esa ocasión, sin el más mínimo rubor, que él tampoco había entendido la tan mentanda introducción, sumamente compleja, y eso que él ya había tenido un diálogo con Karl-Otto Apel.

Aquel seminario preparatorio duró dos semestres, exactamente todo el año 90, durante el cual leímos y trabajamos todo lo que de Apel estaba publicado hasta ese entonces, inclusive sus libros o artículos en alemán que no habían sido traducidos aún al español. De la mano de Apel fuimos haciendo un repaso de los temas más candentes a los cuales la filosofía europea y moderna se estaba enfrentando después de la Segunda Guerra Mundial, es decir, no solo nos enfrentamos al giro lingüístico y al giro hermenéutico, sino a cómo, estos últimos, Apel produjo lo que hoy se conoce como el giro pragmático; es decir, cómo la filosofía contemporánea se enfrentó al paradigma de la conciencia con la cual había nacido, cómo Apel se había hecho cargo de este problema con su obra y cómo, con base en dicho giro, produjo su propia obra. Porque no es Habermas el maestro, sino Apel, y hay que decirlo para reconocer el honor a quien se lo merece ${ }^{3}$. Solo quien no conoce la obra de ambos puede opinar lo contrario.

¿De qué trataba el giro pragmático operado por Apel? Debo decir que ese problema no lo hubiese entendido de no haber sido por haberlo conocido personalmente, y haber tenido la oportunidad de conversar con él las tantas veces que vino a México. Hay temáticas que no se las entiende a partir de un libro, sino solo cuando el maestro las ilumina con su exposición. Ello, en parte, tiene que ver con su vida, con la experiencia vital que le tocó enfrentar; como dice Hegel, la razón solo es capaz de tematizar aquello que previamente ha experimentado. Lo que había descubierto Apel en vida, como experiencia vital, fueron las consecuencias funestas y atroces que produce, en el ámbito de la política y la vida cotidiana, el principio del individuo o de la egoidad, presupuesta como fundamento en el paradigma de la conciencia, esto es, cuando se parte sin más de la certeza del individuo en

3 Es Apel quien introduce a Habermas a la temática nueva en la cual ya estaba trabajando desde la década del 50, que planteaba la aparición de realidades en pleno proceso de democratización en la Europa de la posguerra, en las que el problema del hambre, del trabajo y del salario era menor, y por ello el conflicto de la comunicación o del lenguaje con el cual se producían las políticas empezó a cobrar suma importancia. Apel ya había hecho el pasaje hacia la filosofía del lenguaje y la hermenéutica, en cambio Habermas todavía estaba atrapado en la problemática propia de la Escuela de Frankfurt, no por casualidad era en ese entonces asistente de Adorno. 
la investigación, porque el resultado es un callejón sin salida. Una muestra de ello habían sido las Meditaciones cartesianas de Husserl (1979), esto es, la cuasi imposibilidad de la egoidad fundada en sí misma de hacer el pasaje hacia el reconocimiento del alter ego o, como dirá después Lévinas, del otro. Pero en Apel el problema no era teórico sino existencial, y no necesariamente de carácter individual.

Una vez narró con mucha pasión la experiencia que tuvo antes de ir a la Segunda Guerra Mundial. Decía que, entre los compañeros de su generación, en la universidad, había algo así como un acuerdo de por qué no había que ir a la guerra, pues ya se advertía que las decisiones económicas, políticas y bélicas que se tomaban en el gobierno comandado por Hitler, y que estaban afectando no solo a los alemanes sino a toda Europa, prácticamente eran dictadas por un único individuo, haciendo caso omiso de lo que posteriormente él llamaría “comunidad de argumentantes”. Pero de pronto, cuando estaban él y sus compañeros en las aulas, ingresaron a ellas oficiales del ejército llamando a que la juventud alemana se alistara en éste, y la respuesta fue un casi unánime: ¡heil Hitler! Y terminaron yendo a la guerra todos sus amigos y también él. Y fue al Frente Ruso, en el cual posteriormente cayó prisionero. Pero no solo estando en el frente, sino también en prisión, empezó a meditar sobre cómo era posible que grandes sectores de la población, y hasta naciones o países, pudieran estar literalmente sometidos a las decisiones o pensamientos de unos cuantos egos. De pronto tuvo la intuición de que el problema no era una cuestión de cultura o idiosincrasia, propia de tal o cual pueblo o sector de la población, sino algo mucho más complejo, es decir, un tipo de idea de lo que era racional o correcto, producto de la modernidad.

Una vez que volvió de la guerra, y desde que se habilitó como profesor, empezó a indagar en las propias fuentes de la filosofía moderna, autor por autor, corriente por corriente, hasta dar con el problema: "el paradigma de la conciencia”, nacido con Descartes, que se desarrolló casi sin problema durante toda la filosofía moderna. Se trata de que lo fundamental en el desarrollo de lo que debía ser entendido como racional o racionalidad, en última instancia, estaba fundado en la conciencia del individuo, esto es, que necesariamente antes que las palabras o las argumentaciones estaban los pensamientos, y que estos eran los que daban forma a todo lo que conocemos 
humanamente. Luego se encontró con la obra del segundo Wittgenstein y el último Heidegger, quienes, a su modo, llegaron como producto de una tematización similar al problema del lenguaje. A partir de ellos se desarrollaron líneas en la perspectiva de dicho problema antes que de los pensamientos. Lo que se había empezado a descubrir era el conflicto de la constitución de los pensamientos, de cómo ellos se forman y se desarrollan, es decir, de dónde surgen y qué es lo que está presupuesto en ellos. La respuesta cuasi unánime era que a todo pensamiento humano no solo le presupone un lenguaje, sino que todo pensamiento está constituido por el lenguaje, y que este último "no es solipsista" o individual. Y si no lo es, entonces, ¿qué es? Haciéndose esta pregunta es que encuentra la obra de Charles S. Pierce, quien propone que a todo acto humano le precede siempre una comunidad, incluyendo la del lenguaje, y, tomándola en cuenta, lo que está presupuesto en ella y que se ejerce cotidianamente en el uso del lenguaje es, siempre, una intencionalidad ética y hasta normativa, es decir, valorativa. La temática desarrollada en los dos tomos de La transformación de la filosofía, escritos entre 1955 y 1972, eran ensayos exploratorios en torno no solo de las limitaciones del paradigma de la conciencia, sino de cómo se podía salir de ella hacia otro paradigma. En ese entonces todavía no estaba bien claro para todos en qué consistía el giro pragmático.

De los más de treinta asistentes con los que empezó el seminario, al final fueron seleccionados solo seis trabajos que iban a ser leídos y discutidos con él personalmente, en una serie de jornadas abiertas al público, en la UAM-Iztapalapa, en enero de 1991. A mí me tocó el segundo día. Mi gran descubrimiento en su obra había sido el concepto de "comunidad ideal de comunicación" como el momento siempre presupuesto en cada acto de habla que un interpelante serio opera en la vida real, diaria y cotidiana ${ }^{4}$ (Dussel, 1994). Debo decir que durante ese seminario entendimos, en carne propia, que, para apropiarse de la obra, el pensamiento y el lenguaje de lo que se llama un "pensador", como de hecho lo es Apel, no basta con un añito. Que es de irresponsables o ignorantes pensar o creer que leyendo un artículo o librito de un pensador se puede, sin más, hablar con sentido acerca de su

4 Mi ponencia resumida, que se llamó De la comunidad ideal de comunicación a la comunidad real de comunicación, aparece en el libro colectivo de Dussel (1994) pp. 90 y ss. 
obra o pensamiento ${ }^{5}$. Esto lo digo porque durante el seminario que tuvimos con Apel, en plena discusión con él, es que recién se nos aclararon varias ideas y problemas que creíamos haber entendido leyendo sus libros y no era así. Apel, como maestro que fue en vida, con la paciencia y humildad que le caracterizaban, no dudaba un instante en ponerse a discutir seriamente con uno las ideas que él estaba entablando argumentativamente en su obra, aunque uno fuese alumno de la licenciatura en filosofía, como era mi caso. Debo decir que justo después de ese año de trabajo en el seminario de su obra (no de una mera lectura), y luego de haber discutido personalmente con él y el grupo de compañeros que estuvieron con nosotros esas dos semanas, es que estuvimos preparados para la digestión de su obra. Antes habría sido imposible. Por ello es que muchas veces dije que, tras esa experiencia, todos quedamos "transformados" con La transformación..., inclusive el propio Apel. El diálogo no se detuvo en 1991, sino que continuó hasta el 2002 inclusive, cuando vino por última vez a México y le celebramos su 80 aniversario. La segunda vez que vino al DF, en 1998, pudimos platicar con él más amigablemente, no solo porque se dio cuenta de que nos dimos a la tarea de seguir trabajando su obra, y hasta teníamos unos alumnos apelianos, lo cual le dio mucho gusto, sino porque entonces, a partir de ella, podíamos plantearle otro tipo de problemas dignos de ser pensados. Se acordaba perfectamente de la discusión nuestra, hasta hacía la broma de que cuando le planteaban la posibilidad del diálogo entre la filosofía europea moderna y las filosofías no europeas (diálogo Norte-Sur), como las de los pueblos de tercer mundo, él siempre decía que ya lo estaba haciendo, y que inclusive tenía un alumno aymara, por supuesto que se refería a mi persona. Hacia fines de la primera década de este siglo, cuando un exalumno nuestro fue a hacer su doctorado a Frankfurt sobre la obra de Apel, en una entrevista que le hizo, él se acordaba perfectamente de su alumno aymara y de su "comunidad

5 El caso de Habermas al respecto es ilustrativo. Durante los seminarios que tuvimos con el profesor Dussel sobre Marx, entendimos lo que significa leer a un pensador en sus fuentes y no así a partir de estudios o interpretaciones o, en el peor de los casos, de manuales. Varios de nuestros compañeros hicieron tesis sobre la relación Marx-Habermas y ahí descubrimos que Habermas nunca entendió a Marx, que su lectura siempre fue indirecta, a partir de comentarios, estudios o introducciones, pero nunca leyó a Marx. Desde ese entonces, me río cada vez que leo artículos o libros de gente dizque del pensamiento crítico, marxistas o de izquierda, que citando un parrafito de un artículo se despachan fácilmente con pensadores de la talla de Hinkelammert, Dussel, Marx o el propio Apel. La crítica es algo mucho más complejo de lo que mucha gente cree. 
argumentante andino-amazónica", que le opuso a la "comunidad ideal de comunicación" apeliana.

¿Qué fue lo que seguimos trabajando durante la década del 90? Luego de la discusión y del seminario con Apel, el profesor Dussel se dio perfecta cuenta de que tenía que volver a fundamentar su ética de la liberación de otro modo. Ahora ya no se trataba de que la liberación fuese de los pueblos latinoamericanos o pobres, solamente, sino que ahora tenía que ser mundial o, si no, universal. Hasta antes de la discusión con Apel, este servidor pensaba que, para producir un pensamiento acorde con la realidad que se vive, bastaba con pensar, o con ubicarse con el pensamiento desde el lugar del acontecimiento del cual uno procede. Así, la afirmación de lo propio se convertía en el eje de nuestro pensamiento. En ese entonces todavía no manejábamos el concepto del locus de enunciación. La discusión que tuvimos con él, en enero del 91, sirvió para entender que nuestra posición era, si no etnocéntrica, entonces historicista, y hasta relativista. Él (y su obra es una prueba de ello) es un crítico duro de toda posición relativista, porque si hay algo que caracteriza al pensamiento, en el más alto sentido de la palabra, es su "pretensión" de universalidad, de que lo que se esté pensando pueda servir para todo ser humano posible en proceso de emancipación o liberación, como es el caso nuestro.

Trabajar y recepcionar críticamente su obra durante la década del 90, en la cual dimos varios cursos acerca de ella, sirvió para entender que, si uno se limita a producir un pensamiento relativista, tarde o temprano dejará intactos los derechos del dominador o los fundamentos de la dominación, quedando al final la propia como una posición más entre tantas. Y una posición ética, en sentido fuerte, no puede pretender proponer juicios éticos universales solo para unos pocos, o si no solo para las mayorías dominadas, dejando intactos los derechos del dominador. O dicho en el lenguaje actual de Hinkelammert, si uno entabla con seriedad un proyecto o proceso de liberación, no puede pretender liberar solo al dominado, sino que también hay que liberar al dominador, de lo contrario se deja la subjetividad dominadora del dominador intacta. Y así, este vuelve tarde que temprano a aparecer. Esto es, en pleno apogeo del pensamiento posmoderno y relativista francés -nos referimos a la década de los 90-, que la obra de Apel no solo ya era crítica de ello, sino que mostraba ampliamente su autocontradicción performativa. 
Pero también durante esa década, en diálogo con su obra (que ya no es mera recepción), entendimos la pertinencia y la necesidad de hacer el "giro pragmático” para cualquier intento de crítica o superación de la racionalidad moderna, como racionalidad de dominación. Y otra vez, a partir del diálogo personal con el maestro, entendimos que su obra es también una respuesta a la constante y permanente desintegración de la sociedad moderna, fundada fuertemente en el paradigma de la conciencia. Él insistía, una y otra vez, en que cuando se intenta el diálogo intersubjetivo en la modernidad, los participantes del diálogo, cuando lo entablan, afirman a priori su propia egoidad, negando o subvalorando también a priori la dignidad del otro interlocutor, lo cual igual niega a priori la posibilidad del diálogo. De ahí que a la discusión en la modernidad se le mal llamara diálogo, donde los participantes entablan sus pretensiones no para llegar a un acuerdo o conocimiento, sino para vencer argumentativamente al otro argumentante, lo cual no produce acuerdo/entendimiento, sino disociación, extrañamiento, enajenación y hasta enemistad. En este sentido, para Apel, el diálogo era el lugar donde se entablaban explícitamente las pretensiones éticas, siempre presupuestas, de los participantes.

El problema entonces era cómo superar esta situación o acontecimiento catastrófico que estaba produciendo una idea o fundamentación de la razón y la argumentación. Lo primero que había que cuestionar era la idea de la certeza del individuo (tan en boga hoy por el liberalismo contenido en el neoliberalismo), como punto de partida para la comprensión del fenómeno del lenguaje y del diálogo. De su lectura de Pierce, Apel entendió perfectamente que lo que siempre está presupuesto (de modo ideal) en todo acto humano, inclusive el argumentativo, es una comunidad de argumentantes, a la cual le llamó "comunidad ideal de comunicación”, presupuesta siempre en todo acto humano con sentido y posible de ser inteligido, que sirve como criterio para evaluar cuándo hubo o no diálogo. Esto es, el giro pragmático consistía en el intento o esfuerzo de salir explícitamente de la certeza del paradigma de la conciencia, es decir, de la primacía del yo o del ego, cuando se trata de entablar relaciones con pretensión ética o de justicia. Esto se tornaba fundamental a la hora de querer hablar o argumentar, con sentido, acerca de la posibilidad del diálogo. 
En una discusión que tuvimos acerca del carácter de la pragmática, de si era universal la posición de Habermas o trascendental la posición de Apel, la contestación fue una pregunta, ¿qué tipo de interlocutores presupone cada posición? $\mathrm{O}$, si no, ¿qué tipo, de subjetividad presupone cada posición? La respuesta fue contundente para entender por qué la posición de Apel es más pertinente a la nuestra que la de Habermas; no por casualidad Habermas termina por seguir afirmando, ingenuamente, a la modernidad, y en cambio la posición de Apel puede ser crítica incluso de la modernidad, si se la lleva hasta sus últimas consecuencias. Habermas afirma que la pragmática universal presupone un interlocutor competente en los asuntos en cuestión y, si no es competente o especialista, queda fuera de la discusión. En cambio, para Apel cualquier sujeto con competencia lingüística es competente a la hora de querer entablar sus pretensiones de inteligibilidad, justicia, igualdad, etc., especialmente si está afectado por las consecuencias de tales o cuales actos. Hasta un niño, si es capaz de plantear sus posiciones lingüísticamente hablando, es un interlocutor válido para cualquier discusión que tenga que ver con los asuntos de la comunidad de argumentantes, porque la pragmática es trascendental. Y lo es, no solo porque el argumentante entabla sus pretensiones recurriendo a actos de habla performativos, esto es, propositivos, relacionados con el futuro, las promesas y el compromiso de ser evaluados abiertamente al interior de la comunidad de argumentantes, sino también porque el interlocutor, cuando lo es de verdad, está obligado a reconocer la dignidad absoluta de su interlocutor durante la argumentación, inclusive antes de ingresar en ella. Es decir, únicamente cuando existe el reconocimiento explícito de la dignidad de la subjetividad o humanidad del interlocutor durante la conversación, se puede hablar de diálogo, de lo contrario es imposible. Esto quiere decir que el diálogo presupone no solo el ejercicio de un logos con explícita pretensión de inteligibilidad, o sea de entendimiento, sino de sujetos dialógicos, cuya intencionalidad presupone el reconocimiento explícito de la intencionalidad ética presupuesta en la humanidad y dignidad de los participantes en el diálogo.

Por ello, solamente entonces se podía ver de modo claro por qué es que el diálogo fundado en el paradigma de la conciencia era y es imposible. Se podía entender bien por qué no solo no hubo diálogo entre el primer y el tercer mundo, sino que nunca lo habrá mientras la racionalidad de la 
argumentación esté fundada en el paradigma de la conciencia, que es aquella que afirma, a priori, la egoidad del argumentante como superior y en contra de la humanidad o subjetividad del interlocutor, que a su vez afirma, a priori, la superioridad racional y racial del argumentante, aun antes de ingresar al diálogo. Se entendía mejor, de modo mucho más claro, por qué es que no solo la ciencia social y la filosofía modernas nunca habían dialogado con nuestras culturas, sino también por qué la política y la economía, fundadas en este tipo de subjetividad y de racionalidad, siempre iban a ser de dominación.

Por ello, es que había que hacer el giro pragmático al paradigma de la conciencia, incrustada inclusive en la cultura y la intelectualidad de los pueblos dominados del sur. Debo decir que este tipo de fundamentación filosófica apeliana, tan sofisticada, sutil, fina y bien argumentada, sedujo a muchos de los nuestros, porque intentando partir de nuestro horizonte de comprensión y argumentación, es decir, de nuestro propio horizonte histórico y cultural como fundamentación, con la crítica apeliana terminábamos siendo subsumidos al interior de la nueva fundamentación que la filosofía moderna estaba haciendo. Para ir más allá del pensamiento moderno, había que hacerle un giro al giro pragmático, de lo contrario seguiríamos atrapados al interior de él. Esto es lo que intentó hacer Dussel (1998) en su nueva Ética de la liberación6, la cual presupone la digestión de todo ese debate, y por eso muchos lectores, e inclusive alumnos suyos, no lo entienden aún.

Esta es la deuda que uno tiene con los maestros. Apel nos había llevado hasta el límite del pensamiento moderno, hasta su propia autocontradicción performativa, por eso se entiende que la filosofía actual guarde silencio respecto de su obra, porque no le es pertinente, esto es, socaba inclusive la pretensión de seguir siendo universal, cuando desde la obra de Apel se puede mostrar argumentativamente que nunca lo fue. Hinkelammert primero y luego Dussel fueron quienes dieron el siguiente paso hacia el más allá de esta pragmática, porque había que liberar al giro pragmático de su entrampe moderno, produciendo otro giro. Fue Hinkelammert quien

6 Esta ética amarilla, como le llamamos por su color, ya ha sido traducida a varios idiomas, pero hasta la fecha no ha habido una recepción de esta, sospechamos que es porque en el fondo no se la entiende. Porque esta ética presupone no solo otro Marx, sino haber entendido el giro pragmático que el pensamiento de Apel le hizo a la filosofía moderna, fundada en el paradigma de la conciencia hasta el día de hoy. Decíamos ya en ese entonces que no solo la filosofía tenía que refundarse, sino que, especialmente, la ciencia social en general necesita de nuevos presupuestos conceptuales y categoriales para poder entender y conocer de mejor modo la realidad que nos toca vivir hoy, y con mayor razón el giro decolonial, como veremos. 
primero mostró que a toda comunidad de comunicación o de argumentantes le presupone siempre la vida, es decir, el que los argumentantes puedan entablar lingüísticamente sus pretensiones presupone siempre que estén vivos, y no presupone solo la vida del argumentante, sino la de su familia, pueblo o comunidad. O como también decimos ahora, la existencia o aparecer de cualquier argumentante presupone que este pertenezca siempre y ya a una "comunidad de vivientes", la cual presupone siempre una "comunidad de vida", que no se limita únicamente a seres humanos, sino a los "vivientes" que hacen posible la vida humana en general.

Esto quiere decir que a toda acción con sentido, de cualquier individuo o persona en cualquier cultura o civilización, le presupone siempre una comunidad de vivientes, ya que, en el principio, nunca estuvieron ni están los individuos, sino siempre la comunidad. Antes que el monólogo está siempre el diálogo. Ahora se entendía por qué es que Apel, en toda nuestra discusión, siempre presuponía la existencia de una comunidad "ideal" de comunicación como anticipación, y no una comunidad "real”. Mi posición desde el principio fue que la existencia fáctica de los pueblos originarios es la prueba de que la "comunidad de comunicación real" es, de hecho, principio a partir del cual no solo se puede cuestionar al paradigma de la conciencia, sino producir otro ejercicio o concepción de lo que es la racionalidad y la realidad, la cual presupone en concreto otra idea o noción de subjetividad y de sujeto, pero también de realidad viviente. Ahora, a esta nueva idea de racionalidad le llamamos la "racionalidad material de la vida", el más allá de la racionalidad formal propia de la modernidad, que desde el principio ha partido del individuo y no así de la comunidad.

Toda esta discusión sirvió, entre otras cosas, para que Dussel produjera, a partir de la digestión de lo mejor del pensamiento moderno contemporáneo, otro tipo de fundamentación distinto del que la filosofía moderna ha logrado hasta el día de hoy. En el caso nuestro, sirvió para entender que una posición como la nuestra, con seria y honesta pretensión de justicia, no puede ser solo para un grupo, etnia, o cultura, sino para la humanidad toda, es decir, debe tener una seria pretensión de universalidad, la cual no lo es de hecho, por ello es una pretensión, y por lo mismo tiene que estar abierta a la posibilidad del distanciamiento autocrítico evaluativo, a partir del cual se pueda poner a la altura de la historia y los acontecimientos. Entonces veíamos que la vida, o 
la comunidad de vivientes era, como un dato de la existencia, trascendental a toda forma de vida humana, pero que ya no tenía un carácter formal, sino material, porque la vida es el "principio de materialidad" por excelencia, con base en el cual se pueden desarrollar todo tipo de formalidades o formalizaciones posibles. Por tal razón es que, a partir de Hinkelammert, empezamos a utilizar el concepto de trascendentalidad material, que como vida está detrás, o como presupuesto de toda forma de vida en concreto, y que para que ella sea factible necesita siempre de su momento evaluador o crítico. De ahí que ahora la pretensión de la vida para todos y todas requiere, de modo trascendental, la necesidad del ejercicio de la crítica, que siempre es autocrítica o autoevaluación de las pretensiones con las cuales uno opera o impulsa el ejercicio de una forma de vida en concreto.

Ya cuando, a fines de los 90, Apel publicó su Auseinandersetzungen. In Erprobung des transzendentalpragmatischen Ansatzes, su pensamiento había dado su propio giro? . Lo mismo pasó con la obra de Dussel, de Hinkelammert y hasta de la mía. Cuando nos vimos en abril del 2002, aquí en México, y le celebramos su 80 aniversario, se notaba que en parte estaba satisfecho con su obra, porque todos estos diálogos le habían permitido repensar ciertos temas o problemas supuestamente superados o aclarados, y sabía que había que ir más allá de ellos, como el del diálogo que él operó entre Wittgenstein y Heidegger, primero en La transformación de la filosofía y luego, treinta años después, en Auseinandersetzungen... así como con otros temas ${ }^{8}$. Según su propio testimonio, si él tuvo un aporte en lo que se llama la filosofía, estaría en esa obra, y no así en la anterior, que habría sido preparatoria. La Ética de

7 Hasta ahora no ha sido traducido el libro de modo íntegro, pero varios de los trabajos contenidos en este, tan importante libro del Apel más maduro, han sido traducidos y publicados en España y Argentina. Ver, por ejemplo: Apel, Karl-Otto. Apel versus Habermas. Ed. Comares. Granada. 2004; también: Apel, Karl-Otto. Semiótica trascendental y filosofía primera. Ed. Síntesis. Madrid. 2002. Asimismo: Apel, Karl-Otto. Semiótica filosófica. Ed. Prometeo. Buenos Aires. 2008. Para trabajos posteriores a La transformación... y a Auseinandersetzungen..., ver Apel, Karl-Otto. Paradigmas de filosofía primera. Ed. Prometeo. Buenos Aires. 2013.

8 Cuenta el professor Dussel, a modo de anécdota, que hace algunos años en una conferencia en Europa donde estuvieron invitados tanto Habermas como Apel, después de una intervención de Habermas, Apel le dijo que su exposición había sido bien eurocéntrica. Esto es, Apel ya podía distinguir cuándo una posición era meramente europea, o sea local, y no así universal. Parte del eurocentrismo consiste en confundir lo europeo con lo humano en general. Parte de nuestra crítica al eurocentrismo consiste en afirmar que lo que produjo la Europa moderna no es en sí mismo universal, racional o bueno para toda la humanidad. 
la liberación (Dussel, 2004) ya no dialogó con esta otra parte9 . Queda pues como una tarea pendiente.

Cuando a fines de los 90 y principios de este siglo XXI surgió con fuerza el pensamiento decolonial, se nos ocurrió en varios de los cursos de Dussel y hasta de pláticas con varios amigos y colegas que, así como el principio material de la vida había que elevarlo a principio universal, así también había que hacerle el giro transmoderno o decolonial al giro pragmático. Lo primero requiere producir otra idea o noción de fundamentación. No se puede fundamentar con el mismo tipo formal de fundamentación, lo que se pretende fundamentar de modo material. Se necesita otro tipo que desfonde y ponga en crisis el modo habitual, es decir, que para ello la filosofía necesita seguir transformándose. Lo segundo requiere que, la intencionalidad de producir un pensamiento transmoderno o decolonial como pretensión seria haga previa o paralelamente el giro pragmático (que llamamos como el pasaje o giro de la sociedad a la comunidad), porque, de lo contrario, esta intencionalidad estará presuponiendo ingenuamente el paradigma de la conciencia, que ha sido superado ya por el giro pragmático. Esto es que el pasaje de la individualidad (moderna) a la comunidad (trans moderna) requiere afirmar explícitamente que a toda individualidad o egoidad le presupone siempre una comunidad de vida, presupuesta siempre de modo fáctico en el aparecer de cualquier individuo.

No basta con afirmar positivamente a la comunidad, cuando no se ha salido explícitamente de la pretensión de dominio contenida como presupuesto en el paradigma de la conciencia. De ahí que no sea casual que muchos críticos de izquierda, del capitalismo y el neoliberalismo, sigan afirmando ingenuamente al liberalismo moderno y sus libertades individuales, ya que, en el fondo, afirman positivamente la pretensión de dominio contenida en la subjetividad del sujeto que produjo al capitalismo y la propia de la modernidad, las cuales se han erigido a costa de la negación sistemática de toda forma de vida comunitaria.

9 Paralelamente, en el 2004 se publicaron todos los trabajos tanto del profesor Dussel como, el profesor Apel, con los cuales se hizo el diálogo entre la ética del discurso y la ética de la liberación (Cfr. Karl-Otto Apel y Enrique Dussel, Ética del discurso y Ética de la liberación). Para las siguientes generaciones queda como tarea pendiente exponer no solo lo que se discutió en esos años, sino cómo a partir de esa discusión se puede seguir desarrollando un pensamiento crítico con fuerte pretensión ética y de liberación, que ayude a superar el entrampe racional al cual nos condujo la racionalidad moderna. 
Este último no es un problema solamente teórico, sino fundamentalmente epistemológico, esto es, en el núcleo de muchos conceptos y categorías que habitualmente usamos cuando queremos hacer la crítica decolonial, por ejemplo, todavía están metidos como prejuicios, es decir, como presupuestos a priori, los principios del paradigma de la conciencia, que son aquellos sobre los cuales se yergue la pretensión de dominio propia de la racionalidad moderna. El futuro del giro decolonial depende, en parte, de que se haga también el giro pragmático, de que categorialmente se pueda superar, por dentro y de modo inmanente, el carácter dominador de la racionalidad moderna, porque no basta con denunciarlo, hay que mostrar con conceptos y categorías el porqué de la necesidad de producir otra lógica de la argumentación, de la producción de conocimientos, que superen fácticamente el tipo de conocimiento y de marco categorial del cual se sirve y fundamenta el pensamiento de dominación. Esto presupone, a su vez, que el agumentante no solo haya producido otros conceptos y categorías como objetos, sino que la forma de argumentación, de razonamiento, de sentimiento y pensamiento del argumentante presuponga este otro tipo de subjetividad, más allá de la egoidad de la subjetividad moderna.

Si algo aprendimos con el maestro Apel, y por ello lo recordamos siempre, es que el argumento con el cual nos oponemos al oponente argumentante (en nuestro caso al argumento o conocimiento del dominador) tiene que estar fundamentado de tal modo que hasta el dominador se dé cuenta de su propia autocontradicción; así es como podemos desarmarlo argumentativamente. Sin embargo, la experiencia histórica y política de hoy nos está mostrando que el contra argumentante, como subjetividad egocéntrica, no solo está en el primer mundo, sino que inclusive está entre nosotros, y es aquel que, luchando por un mundo justo, sigue creyendo en las ilusiones de la modernidad, esto es, en su subjetividad sigue presupuesta o escondida la lógica de la dominación propia de la modernidad/colonialidad.

Ahora que Apel habita en la literal trascendentalidad infinita y universal, a nosotros nos toca continuar trabajando en las tareas inconclusas que los grandes maestros siempre dejan a sus discípulos. El fascismo a la Hitler ahora se ha modernizado también, y se ha desarrollado y globalizado con el neoliberalismo a escala mundial, por ello urge producir otro marco categorial que desmonte en regla esta nueva forma de dominación. Para 
ello, la obra de los grandes maestros, como en vida fue Karl-Otto Apel, es un buen ejemplo por seguir.

\author{
Tlalpan de Cuicuilco \\ Meshico Tenochtitlán \\ Mayo del 2017
}

\title{
Referencias
}

Apel, K. O. (1985). La transformación de la filosofía. Tomos I y II. Madrid: Taurus.

Dussel, E. (1994). Debate en torno a la ética del discurso de Apel. México: Siglo XXI.

Dussel, E. (1998). Ética de la liberación. En la edad de la globalización y la exclusión. Madrid: Trotta.

Dussel, E. (2004). Ética del discurso y ética de la liberación. Madrid: Trotta

Husserl, E. (1979). Meditaciones cartesianas. Madrid: Ediciones Paulinas. 